\title{
Análise do perfil dos alunos ingressantes no curso de Licenciatura em Desenho da UFRJ em 2017
}

\section{Analysis of the profile of first period students for teachers of Drawing at the UFRJ in 2017}

\author{
Mariane Brito Azevedo Borges \\ Programa de Pós-Graduação em História das Ciências e das Técnicas e Epistemologia \\ (HCTE), Universidade Federal do Rio de Janeiro (UFRJ) \\ mariane.azevedo@eba.ufrj.br \\ orcid.org/0000-0002-9802-4187
}

Resumo. O curso da Licenciatura em Educação Artística - Habilitação Desenho da UFRJ oferece 36 vagas ao ano através do Exame Nacional do Ensino Médio. O presente artigo tem por objetivo analisar o perfil dos alunos ingressantes no ano de 2017, em relação as suas expectativas e conhecimento sobre a disciplina a qual estarão aptos a lecionar no final do curso. Esta análise, feita através de questionário, é o ponto de partida de um estudo que busca valorizar tal disciplina que, muitas das vezes, é desconhecida ou aparece camuflada em outras.

Palavras-chave: Educação, Currículo, Curso de licenciatura em desenho, Interdisciplinaridade.

Abstract. The UFRJ's Undergraduate Course in Artistic Education with Design Qualification offers 36 places per year through the National High School Exam. The purpose of this article is to analyze the profile of students entering the year 2017, in relation to their expectations and knowledge about the subject they will be able to teach at the end of the course. This analysis, made through a questionnaire, is the starting point of a study that seeks to value such discipline, which is often unknown or camouflaged in others.

Keywords: Education, Curriculum, Degree in design, Interdisciplinarity. 


\section{Introdução}

Os currículos escolares estão voltados para a produção do conhecimento, ou seja, as escolas depositam informação nos alunos e este se tornam meros receptores dessa informação. Outra característica marcante na maior parte dos currículos escolares é a separação das disciplinas, estas são dadas de forma independente, como se não correlacionassem com as outras.

Atualmente, observa-se um movimento por parte das escolas em pautar o ensino oferecido para o preparo específico para inserção do aluno nas universidades. Dessa forma ocorre uma hierarquia dentro do currículo, onde disciplinas são consideradas muito importantes, necessárias ou irrelevantes.

Os requisitos de entrada na universidade pressionam os currículos dos outros níveis educacionais, (assim) esses currículos refletem a mesma ênfase no 'conhecimento técnico'. É esse tipo de conhecimento que acaba sendo visto como tendo prestígio, em detrimento de outras formas de conhecimento, como o conhecimento estético e artístico, por exemplo. (SILVA, 2010)

A formação do aluno não é o principal aspecto dos currículos atuais, observa-se assim o desaparecimento de disciplinas com teor artístico, estético, moral, ético etc. A disciplina Desenho, como ainda é conhecida por poucos devido quase não aparecer nas grades curriculares, vem a ser o foco do estudo do trabalho de tese. Neste artigo, avalio através de questionário, o perfil dos alunos que ingressaram, através do Exame Nacional de Ensino Médio - ENEM, para o curso de Licenciatura em Educação Artística na Habilitação Desenho da UFRJ em 2017. Estes serão os futuros professores desta disciplina que se torna cada vez menos encontrada nas grades escolares.

O objetivo deste questionário é ver se os alunos escolheram o curso com conhecimento do que é Licenciatura e do que é a disciplina Desenho; saber se os mesmos já tiveram contato com a disciplina em si ou se tiveram apenas alguns conceitos dela como parte de outra disciplina "mais importante", bem como o contato com os materiais de desenho. Assim, pode ser avaliado o perfil dos alunos quanto ao conhecimento prévio e sua escolha, bem como o perfil das escolas que ainda lecionam esta disciplina.

\section{Perfil dos alunos ingressantes em 2017}

O questionário foi realizado com os calouros de 2017.1 e de 2017.2 dentro do seu primeiro mês de aula; escolhe-se a aula de Desenho Geométrico Básico para sua realização, pois se pensou que haveria uma maior associação a temática do questionário. $\mathrm{O}$ que foi observado, de maneira informal em anos anteriores, é que na maioria das vezes o aluno não vinculava o curso escolhido com o seu conteúdo e o fato de ser um curso mais técnico. 
Na primeira questão, procurou-se conhecer o porquê da escolha pela Licenciatura e também pela habilitação Desenho. A pergunta gerou dois grupos distintos de respostas. Dentre os ingressantes de 2017.1 é citado a aptidão e o apreço pela docência, outra resposta comum é a proximidade com a Arquitetura. Por outro lado, nos respondentes de 2017.2, não aprece o interesse pela docência, somente o fato de gostarem ou terem habilidade com o Desenho e a proximidade com a carreira que tinham em primeira opção.

A pergunta seguinte quer saber se o curso em questão foi sua primeira opção e qual seria em caso de resposta negativa. A resposta aparece ilustrada no gráfico 1, nele se observa que dos vinte e três alunos que responderam ao questionário, apenas cinco optaram pela Licenciatura em Desenho como primeira opção. Sendo que deste, dois haviam perdido o Teste de Habilidade Específica para os cursos de Desenho Industrial e de Comunicação Visual.

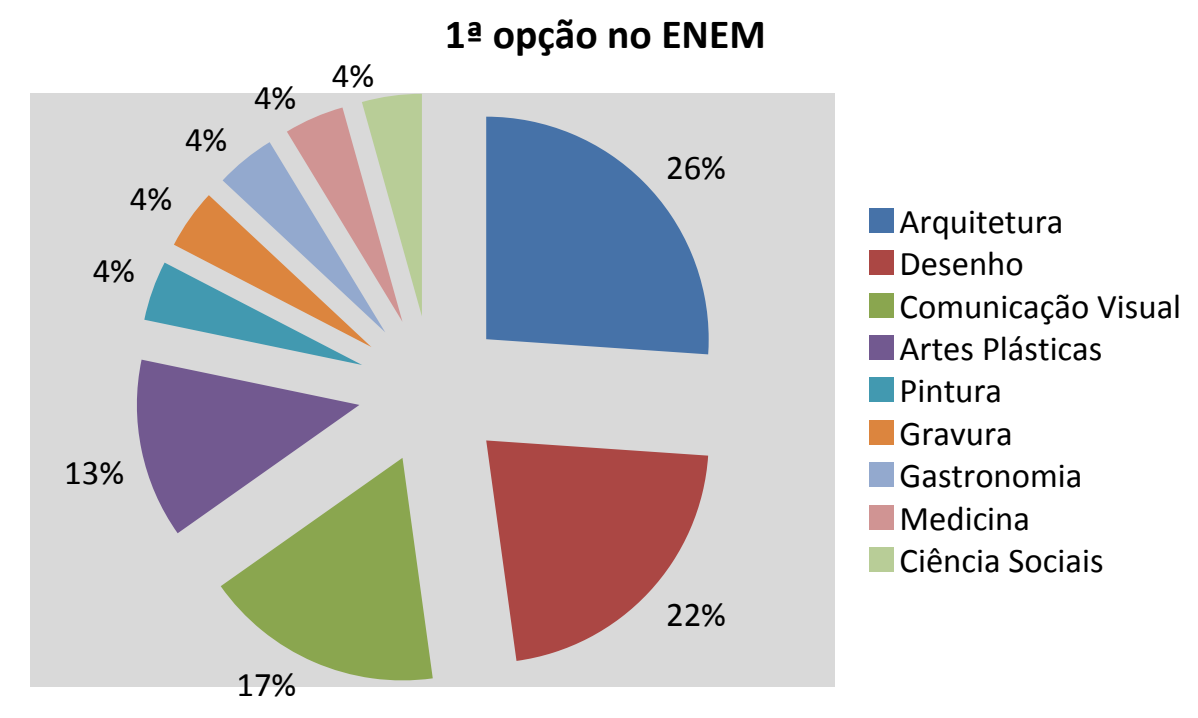

Gráfico 1: Mostra a primeira opção dos entrevistados.

Fonte própria

O questionário segue indagando sobre o Ensino Básico dos respondentes, com o objetivo de conhecer o grau de interação deles com a disciplina analisada. $\mathrm{O}$ gráfico 2 mostra se o Ensino Básico - Ensino Fundamenta (EF) e Ensino Médio (EM) - destes alunos foi obtido na esfera pública ou privada. Pedia-se também o nome da instituição com o propósito de, posteriormente, saber quais escolas lecionam a disciplina. 


\section{Ensino Básico}

$9 \%$

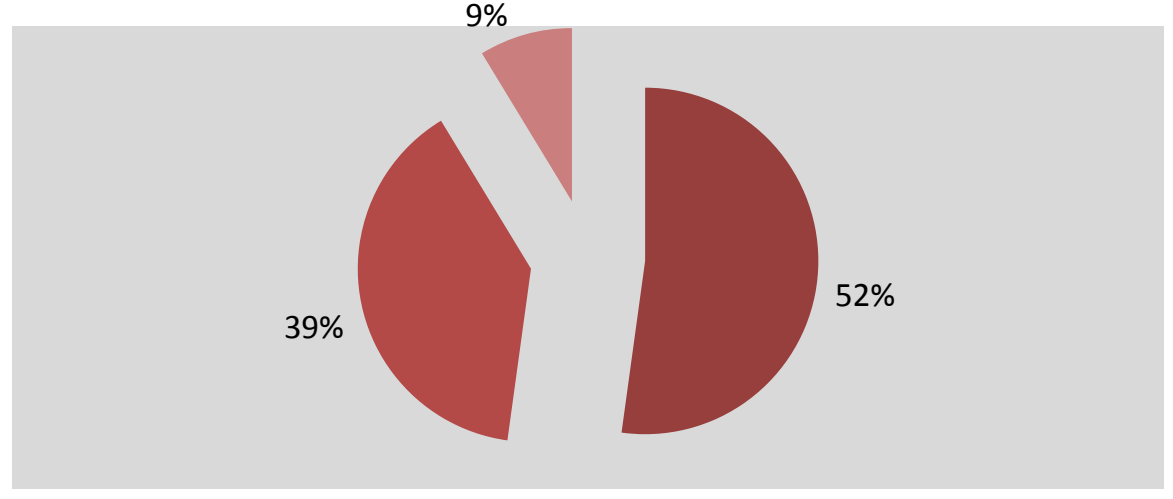

EF e EM públicos

EF e EM particulares

EF particular e EM público

EF público e EM particular

\section{Gráfico 2: Ensino Fundamental e Ensino Médio obtidos em escola pública ou particular}

Fonte própria

Posteriormente, são indagados quanto a terem tido o conteúdo de Desenho na escola como uma disciplina específica ou entremeada em outras ciências. O gráfico 3 nos mostra que apenas $30 \%$ dos alunos tiveram a matéria Desenho e $26 \%$ o conteúdo contido em artes ou matemática. O gráfico 4 ilustra em quais anos, estes alunos, tiveram o conteúdo de desenho em sua escola.

\section{Contato com o Desenho no Ensino Básico}

$4 \%$

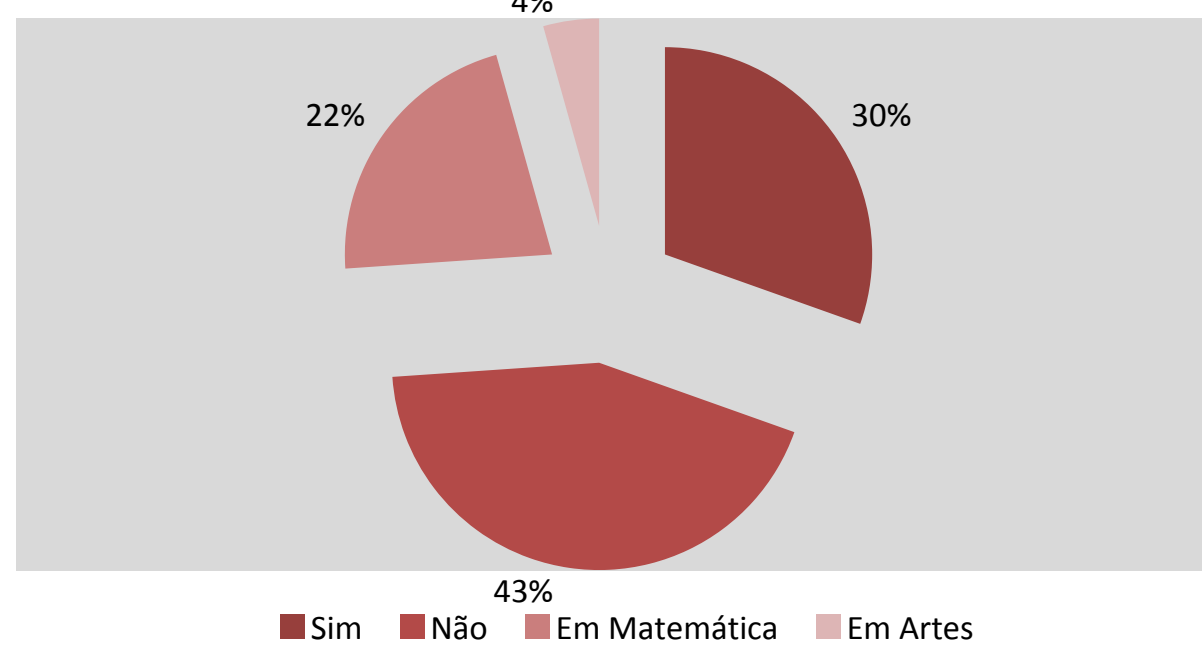

Gráfico 3: Conteúdo de desenho no Ensino Básico

Fonte própria 


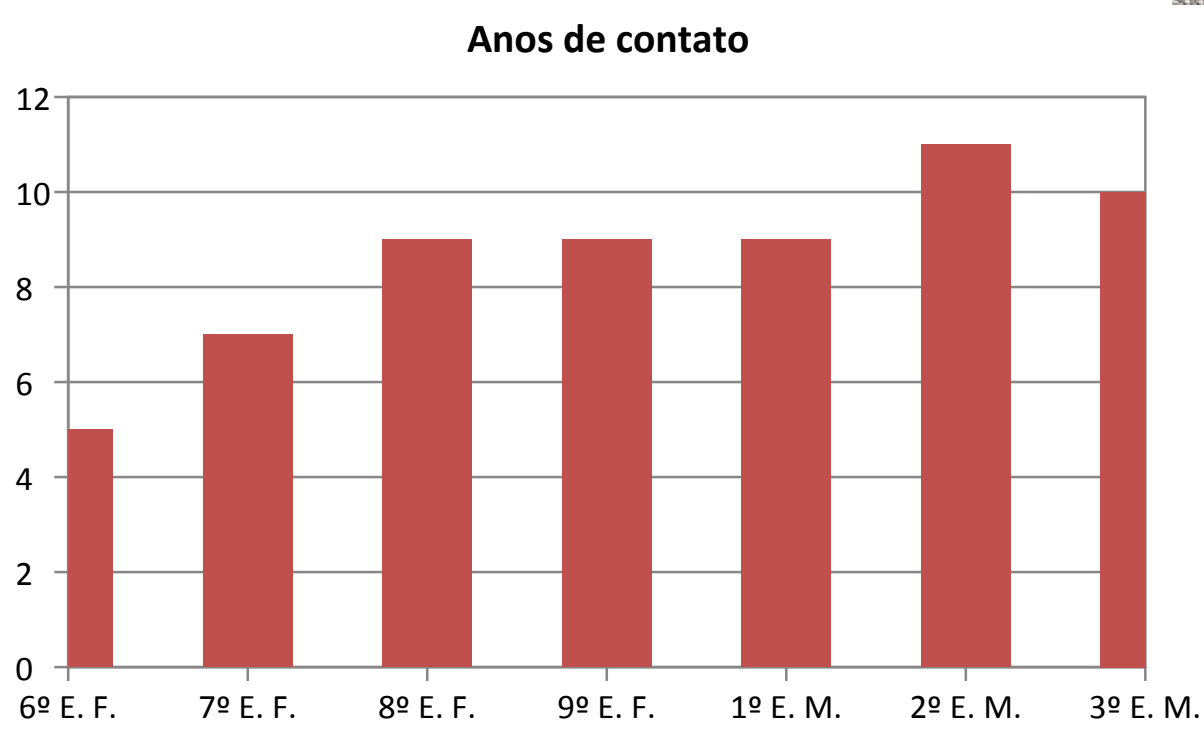

Gráfico 4: Anos que tiveram o conteúdo de desenho

Fonte própria

Abaixo, no gráfico 5, observa-se o contato dos alunos com os instrumentos de Desenho: régua, compasso, par de esquadros, transferidor, escalímetro e curva francesa; independente de terem sido utilizados para o Desenho ou não.

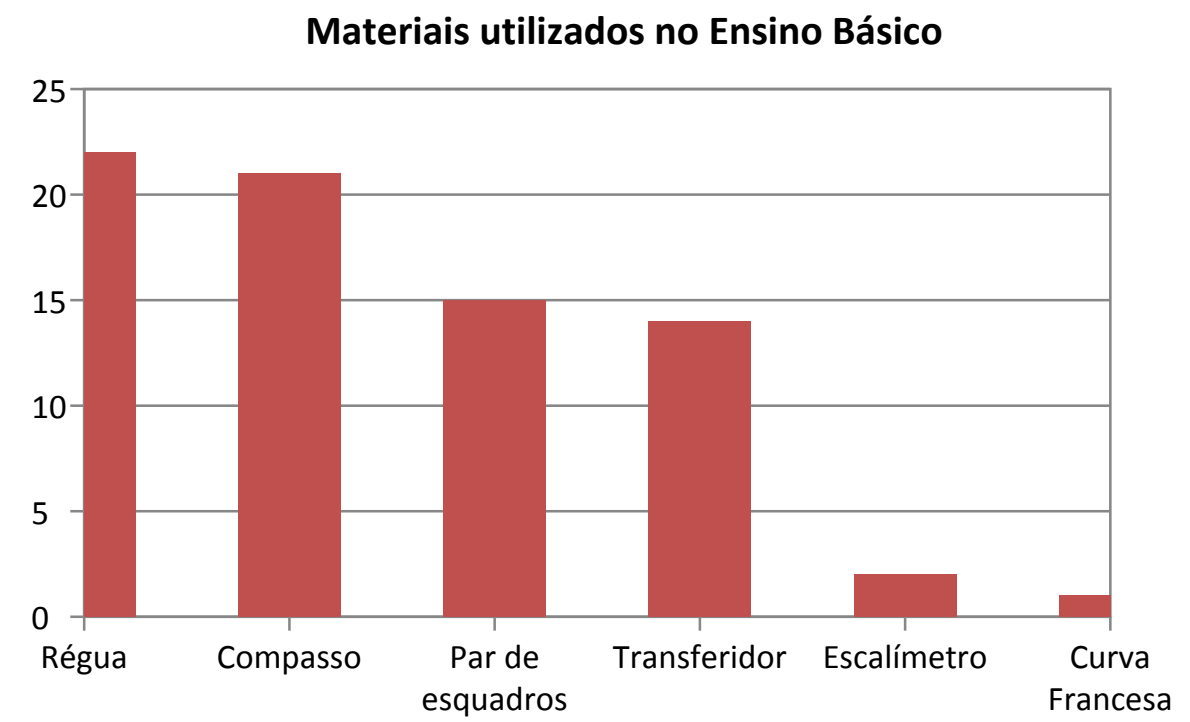

Gráfico 5: O contato dos alunos com os instrumentos de Desenho no Ensino Básico

Fonte própria 
Na parte final do questionário, indago sobre o que esperam do curso e observa-se que muitos não estão muito certo quanto à diferença entre as Habilitações Artes Plásticas e Desenho e que, infelizmente, estão planejando mudar de curso.

Considerando o Desenho como um saber interdisciplinar e concordando com Bemfeito et al. (2013) quando diz que:

A interdisciplinaridade na Educação surge fundamentada no fato de que o conhecimento não é disciplinar. É importante proporcionar ao aluno a percepção de que a fragmentação tradicional encontrada historicamente no processo educativo limita a sua capacidade de fazer relações entre conceitos afins, simplesmente por serem apresentados por disciplinas distintas.

Então, é solicitado que eles avaliem a importância do conhecimento prévio do Desenho para cada área de saber como apresenta o gráfico 6. Analisando este gráfico, comprovase que a ligação entre Desenho e a Engenharia é facilmente percebida, o que não ocorre nas demais áreas.

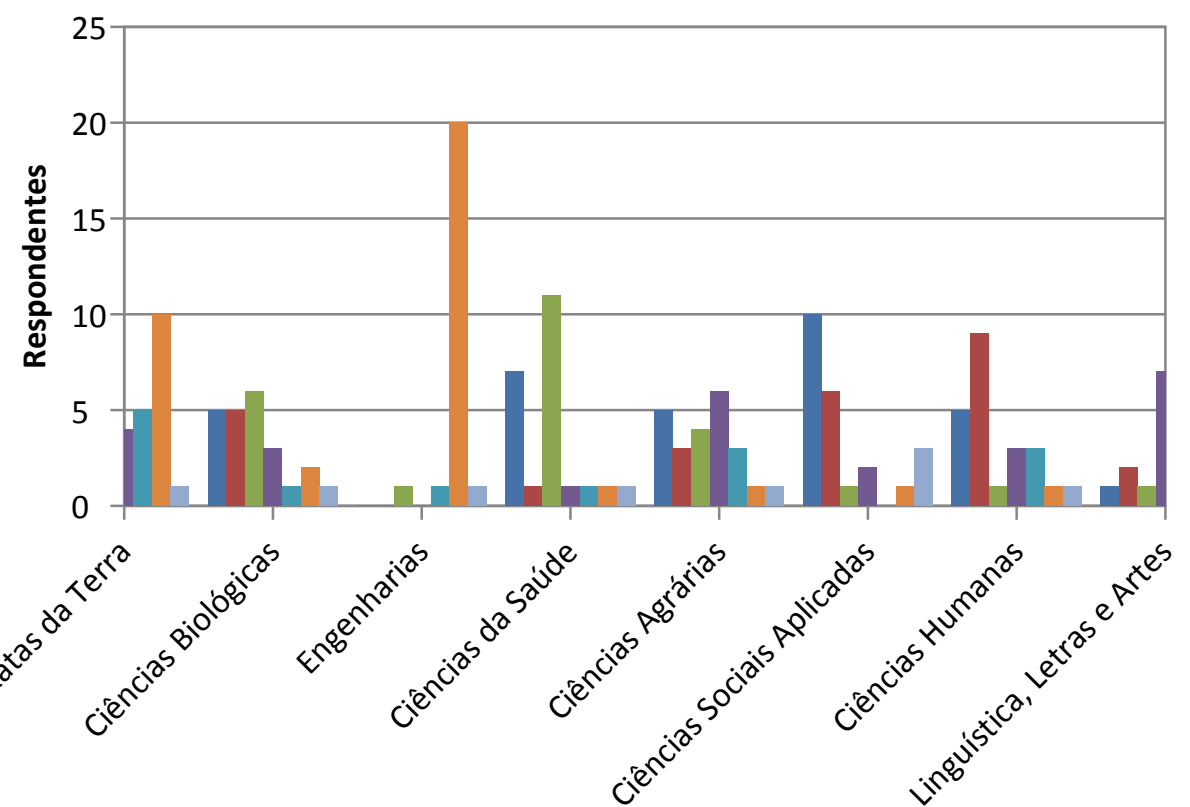

\begin{tabular}{l|l|l|l|l|l|l}
0 & 1 & 2 & $\mathbf{3}$ & 4 & 5 & $\mathrm{~N} . \mathrm{R}$.
\end{tabular}

\section{Gráfico 6: Avaliação dos alunos quanto a importância do Desenho}

Fonte própria 


\section{Conclusões}

Os futuros professores de Desenho não vêm a importância e a interdisciplinaridade do Desenho como um saber básico. Como foi citado, a relação entre o saber e a Engenharia e áreas exatas são percebidas; entretanto, na área médica, por exemplo, a ligação não é vista com tanta facilidade. Contudo, este conhecimento técnico está presente na anatomia humana, na forma dos vírus e como esta pode nos infectar, bem como nas tomografias, ressonâncias, raios-X, etc.

Esse estigma que se pretende rebater em trabalhos futuros, com a comprovação do valor deste saber. Sendo assim, será mostrado que este conteúdo deveria estar presente em todos os currículos escolares de forma interdisciplinar. Uma vez que, acredito que o currículo não deva ser tratado como uma coleção de disciplinas, mas sim de forma integrada, sem nítidas distinções. Conforme a perspectiva culturalista sobre o currículo:

Nessa visão, o conhecimento não é uma revelação ou um reflexo da natureza ou da realidade, mas o resultado de um processo de criação e interpretação social. Não se separa o conhecimento supostamente mais objetivo das Ciências Naturais e o conhecimento supostamente mais interpretativo das Ciências Sociais ou das Artes. Todas as formas de conhecimento são vistas como resultado dos aparatos - discursos, práticas, instituições, instrumentos, paradigmas - que fizeram com que fossem construídas como tais. As implicações dessa perspectiva não devem ficar restritas à análise. É impossível pensar num currículo que enfatizasse precisamente o caráter construído e interpretativo do conhecimento.

Uma vantagem de concepção de currículo inspirada nos Estudos Culturais que as diversas formas de conhecimento são, de certa forma, equiparadas. (SILVA, 2010)

\section{Referências}

BEMFEITO, A. P., ESTEVES, F. C. e OLIVEIRA, R. C. B. de. A interdisciplinaridade como prioridade na formação do professor de física: o caso do curso de Licenciatura em Física do IFRJ - Campus Volta Redonda. In: SCIENTIARUM HISTÓRIA VI, 2013, Rio de Janeiro. Livro de anais do Scientiarum História VI, Rio de Janeiro: UFRJ,2013.

em: http://www.hcte.ufrj.br/downloads/sh/sh6/CLIQUE AQUI.html. Acesso em: 27 abr. 2020. 
SILVA, Tomaz Tadeu da. Documentos de Identidade: uma introdução às teorias do currículo. 3. ed. 1. reimp. Belo Horizonte: Autêntica, 2010. 156 p. 